\title{
THE METHOD OF REMOVAL YTTRIUM (III) AND YTTERBIUM (III) FROM DILUTE AQUEOUS SOLUTIONS
}

\author{
Olga Lobacheva' ${ }^{1}$, Natalia Dzhevaga' ${ }^{1}$ Aleksandr Danilov' \\ 1 National Mineral Resources University (Mining University), Vasil'evsky Island, 21 line 2, Saint-Petersburg, \\ 199106 Russia, e-mail: olga-59@yandex.ru, dzhevaga331@mail.ru, twixsek@mail.ru
}

Received: 2015.12 .22

Accepted: 2016.03.04

Published: 2016.04.01

\begin{abstract}
Yttrium (III) and ytterbium (III) cations ion flotation from diluted aqueous solutions in the presence of chloride ions using sodium dodecyl sulfate as collector agent were studied. Y (III) and Yb (III) distribution and recovery coefficients as a function of aqueous phase $\mathrm{pH}$ value at different sodium chloride concentrations were received. Yttrium (III) and ytterbium (III) chloro and hydroxo complexes instability constants were calculated. The calculation of separation coefficient at $\mathrm{pH}$ specified values depending on chloride ion concentration was conducted. Maximum separation coefficient was observed when chloride concentration of $0.01 \mathrm{M}$ is 50 at $\mathrm{pH} \mathrm{7.8.} \mathrm{K}_{\text {sep }}$ is minimal in nitrate medium ans is 3 at $\mathrm{pH}$ 7.0. At sodium chloride concentration of $0.05 \mathrm{M} \mathrm{K}_{\text {sep }}$ is 9 at $\mathrm{pH} 7.8$.
\end{abstract}

Keywords: ion flotation, sodium dodecyl sulfate, distribution coefficient, separation coefficient, removal.

\section{INTRODUCTION}

Ion flotation is a process based on adsorption at liquid-gas phase boundary of surfactant and inorganic compound ions reaction products. The method is widely used for recovering substances from solutions with concentrations of $10^{-2}-10^{-8}$ $\mathrm{mol} / \mathrm{l}$. Ion flotation is based on recovering ion attraction by oppositely charged collector ions that had attached to the surface of air or gas bubbles that are let through the solution [Gol'man 1982]. Various classes of surfactants are used as collector agents. Ion flotation method permits recovering non-ferrous, rare-earth and heavy metal cations from diluted aqueous solutions and industrial waste waters.

Rare-earth elements are widely used in different branches of industry. Thus lanthanum, cerium and yttrium are used for manufacturing glass, ceramics, catalysts; samarium is used while manufacturing magnets and lasers; europium is used when manufacturing luminophor; holmium and erbium are used when manufacturing ceramics and in nuclear industry. It should be noted that all Russian rare-earth deposits are part of complex deposits, whose processing does not include recovering rare-earth elements. For example, a joint-stock company 'Apatite' is a large mining complex whose sphere of activity are booty and enriching of apatite-nephelites ores of Hibiny deposits, production apatite and nephelite concentrates, and also other mineral concentrates - syenite, titaniummagnetite. A nephelite concentrate containing no less than 28,5 percent of $\mathrm{Al}_{2} \mathrm{O}_{3}$ is used for the production of aluminum, soda, potash, cement, phosphoric-potassium fertilizers, coagulants of containing an aluminium, brick wares, glass wares, rare-earth elements, different salts of aluminium and other foods outside a joint-stock company 'Apatite' [Danilov et al. 2015].

Multipurpose use of mineral raw materials is the most important direction for resource-saving in new millennium. Separated pure rare-earth elements have extrinsic value. That is why an increase in efficiency of separation of rare-earth elements with similar properties is a pressing problem, permitting decreasing the cost of individual rare-earth elements and their oxides, and expand 
the possibility of their use. When employing ion flotation high separation factors for rare-earth elements are not observed [Chirkst et al. 2009a]. Studying of chloride ions influence on ion flotation process is of interest.

\section{MATERIALS AND METHODS}

Ion flotation process was conducted in mark 137 V-FL laboratory flotation machine with a cell of $1 \mathrm{dm}^{3}$ for 5 minutes. Chemically pure 0.001 $\mathrm{mol} / \mathrm{l}$ yttrium and ytterbium nitrates solutions were used as standard test solutions. Solution volume was $200 \mathrm{ml}$. Dry sodium dodecyl sulfate combining both collector and foaming agent properties with general formula $\mathrm{C}_{12} \mathrm{H}_{25} \mathrm{OSO}_{3} \mathrm{Na}$ was used as a surfactant. Its concentration conformed to stoichiometry of the following reaction:

$$
\mathrm{Me}^{3+}+3 \mathrm{DS}^{-}=\mathrm{Me}(\mathrm{DS})_{3}
$$

i.e. it is $0.003 \mathrm{M}$ ( $\mathrm{DS}^{-}-$dodecyl sulfate ion). Sodium chloride was also added to initial solution at a rate corresponding to the concentration of 0.01 and $0.05 \mathrm{~mol} / \mathrm{l}$. The received froth and chamber products were separated and analyzed. The froth was destroyed by using $1 \mathrm{M}$ sulphuric acid. Rare-earth elements concentration was determined by photometric method with arsenazo III [Savin 1966]; chloride ions concentration - by mercurimetric titration method with mixed indicator ( 0.5 mass \% of diphenylcarbazide alcohol solution and 0.05 mass $\%$ of bromphenol blue) [Kresh- kov 1976]; dodecyl sulfate ion concentration - by potentiometric titration method by $0.002 \mathrm{M}$ cetyltrimethylammonium chloride solution with ionselective electrode, consisting of silver-chlorideEVL-1M3, put into $\mathrm{NaDS}$ and $\mathrm{NaCl}$ solution, and membrane, selective to DS ion. The membrane was manufactured by Ionometry Laboratory of St. Petersburg State University Department of Physical Chemistry [Timofeev et al. 1978]. The value of $\mathrm{pH}$ solutions $\mathrm{pH}$ value ranges from 4 to 9 in increments of 0.5 and adjusted by nitric acid or sodium hydroxide solution.

Metals cations distribution coefficients between froth and chamber products were calculated by $\left[\mathrm{Me}^{3+}\right]$ concentration in the froth product relative to $\left[\mathrm{Me}^{3+}\right]$ concentration in chamber residue in accordance with formula [Zolotov 2004]:

$$
D=\frac{C_{o r g}}{C_{a q}}
$$

and separation coefficient

$$
K_{\mathrm{Me}_{1} / \mathrm{Me}_{2}}=\frac{D_{\mathrm{Me}_{1}}}{D_{\mathrm{Me}_{2}}}
$$

In Figures 1 and 2 distribution coefficients as a function of $\mathrm{pH}$ at different sodium chloride concentrations for yttrium and ytterbium cations are shown.

When flotating yttrium (III) cations in acidic medium at $\mathrm{NaCl}$ concentration of $0.01 \mathrm{M}$ in the range of $\mathrm{pH}<6.7$ the recovery is near zero. The abrupt jump of $\mathrm{K}_{\text {distr }}$ is observed at $\mathrm{pH}$ 6.7. Max.

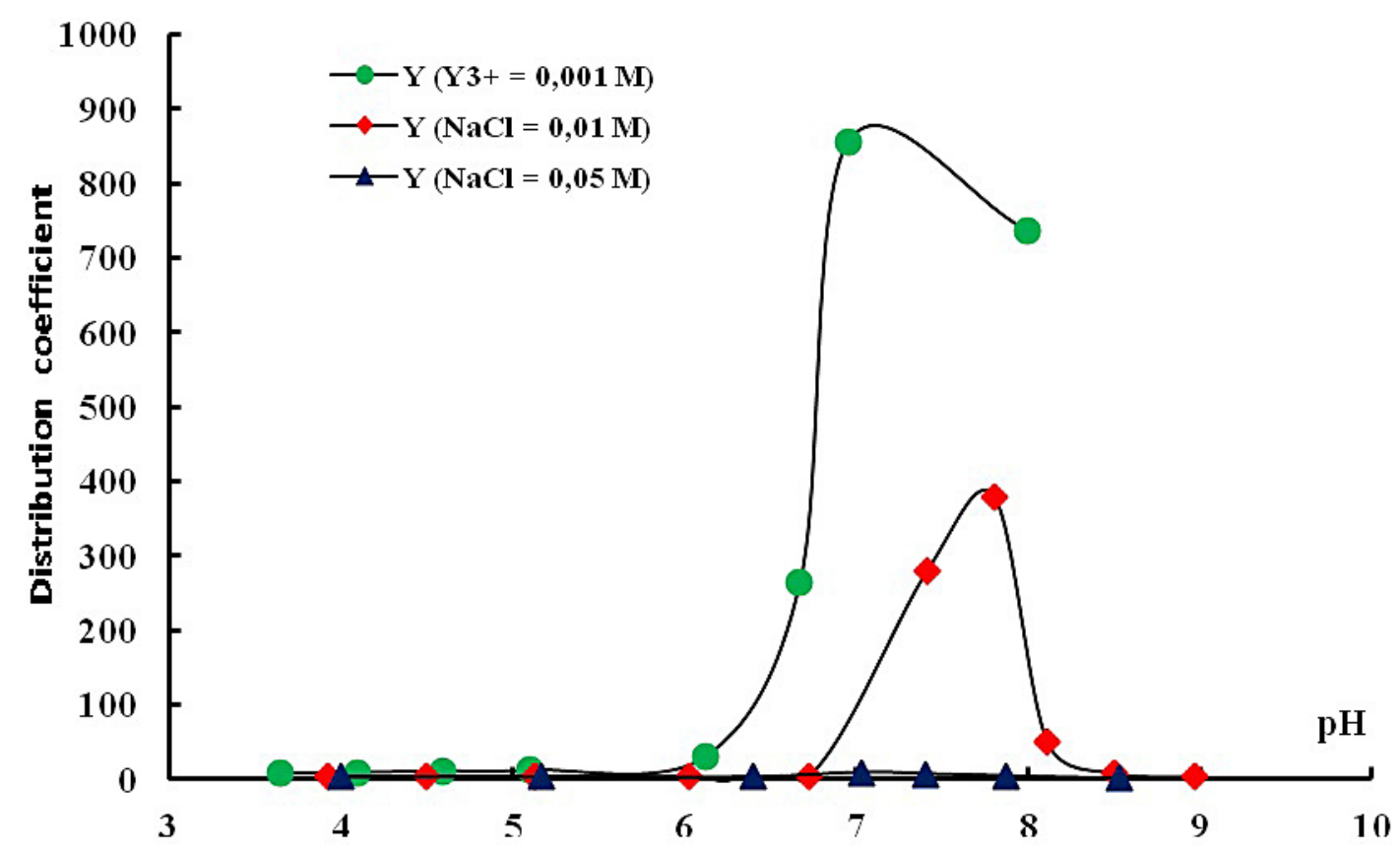

Figure 1. Yttrium $\mathrm{K}_{\text {distr. }}$ as a function of $\mathrm{pH}$ at different chloride concentrations 


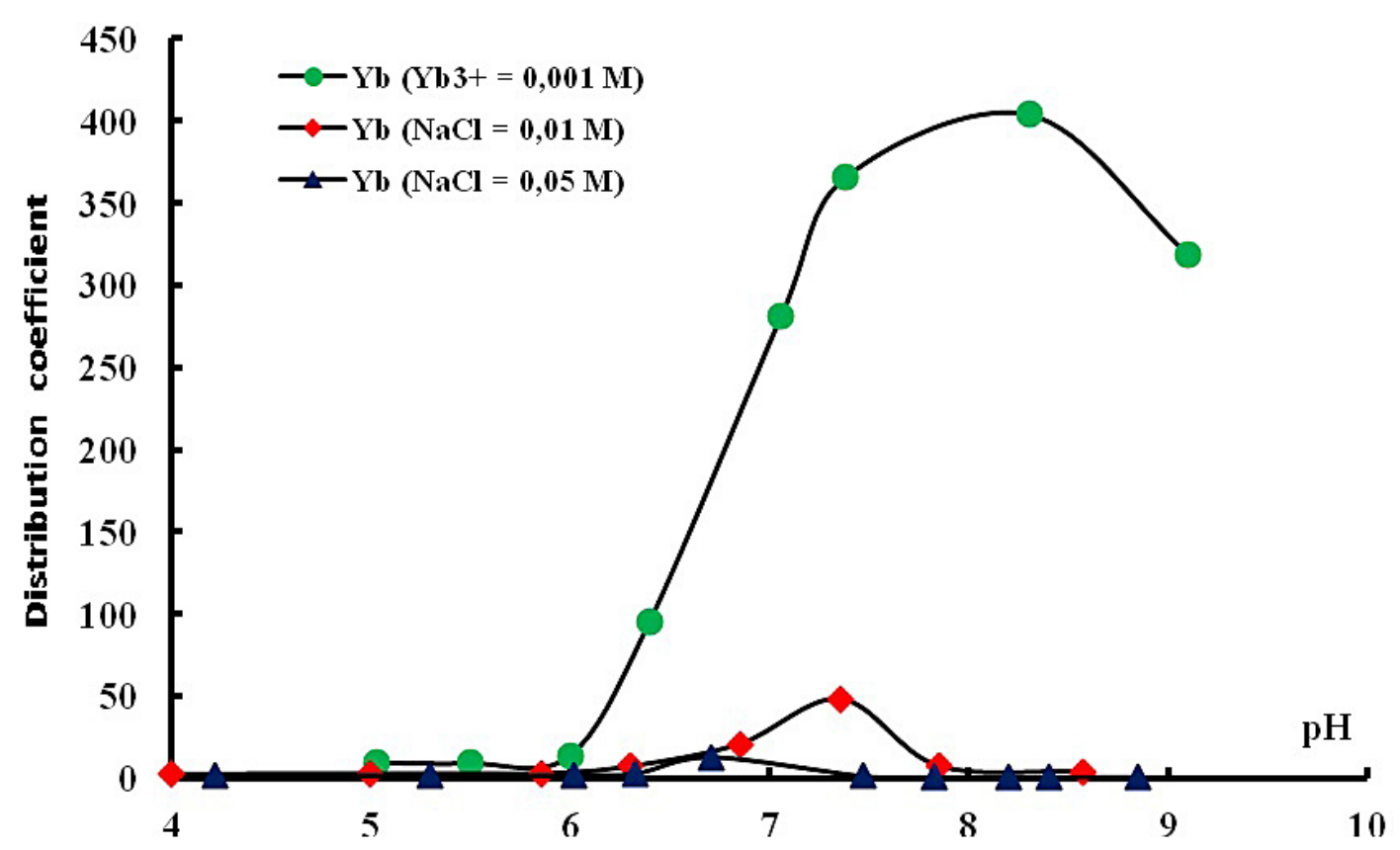

Figure 2. Ytterbium $\mathrm{K}_{\text {distr. }}$ as a function of $\mathrm{pH}$ at different chloride concentrations

$\mathrm{K}_{\text {distr }}$ is 379 at $\mathrm{pH} 7.8$, and 856 in nitrate medium at $\mathrm{pH}$ 6.95. Chloride ions suppress yttrium (III) cations recovery to froth and shift $\mathrm{pH}$ of maximum recovery to the region of high values from 6.95 in nitrate medium to 7.8 at $\mathrm{NaCl}$ concentration of $0.01 \mathrm{M}$. When increasing sodium chloride concentration up to $0.05 \mathrm{M}$, yttrium (III) cations recovery to froth increases significantly. In the range of $\mathrm{pH} 4.0-9.0$ the $\mathrm{K}_{\text {distr }}$ does not exceed 10. $\mathrm{pH}$ of maximum recovery at chlorides concentration of $0.05 \mathrm{M}$ shifted insignificantly to the region of high values from 6.9 in nitrate medium up to 7.0.

Ytterbium (III) cations recovery at $\mathrm{NaCl}$ concentration of $0.01 \mathrm{M}$ starts at $\mathrm{pH} 5.9$ and reaches the highest value of 48 at $\mathrm{pH}$ 7.4. Maximum $\mathrm{K}_{\text {distr }}$ at chloride ions concentration of $0.05 \mathrm{M}$ is 12 at $\mathrm{pH}$ 6.7. In the range of $\mathrm{pH}$ values from 4 to 6 and from 7.5 to 9 recovery is near zero.

\section{RESULTS}

In Table 1 the results of yttrium and ytterbium cations distribution coefficients calculations between froth pulp and chamber residue, onset and maximum recovery $\mathrm{pH}$ value, complexing and hydrating $\mathrm{pH}$ are shown.

Yttrium recovery in the absence of chloride ions at maximum recovery $\mathrm{pH}$ of 6.9 occurs in a form of $\mathrm{YOH}(\mathrm{DS})_{2}$, and at chloride concentrations of $0.01 \mathrm{M}$ in a form of $\mathrm{Y}(\mathrm{OH})_{3}$, because $\mathrm{pH}_{\text {hydr }}$ and $\mathrm{pH}_{\text {compl }}$ are 7.2 and 6.3 respectively [Kresh- kov 1976]. At maximum recovery $\mathrm{pH}$ of 7,0 at chloride ions concentration of $0.05 \mathrm{M} \mathrm{Y}(\mathrm{OH})_{2} \mathrm{DS}$ goes into the froth, because $\mathrm{pH}_{\text {compl }} \mathrm{Me}(\mathrm{OH})_{2}^{+}$is 7.0, and $\mathrm{pH}_{\text {hydr }}$ is 7.2 [Gol'man 1982].

Ytterbium (III) hydroxo dodecyl sulfates $\mathrm{YbOH}(\mathrm{DS})_{2}$ go into the froth up to $\mathrm{pH}_{\text {compl }}$ $\mathrm{Me}(\mathrm{OH})_{2}^{+} 6.3$, ytterbium (III) digidroxo dodecyl sulfates $\mathrm{Yb}(\mathrm{OH})_{2} \mathrm{DS}$ in the range of $\mathrm{pH}$ from $\mathrm{pH}_{\text {compl }} \mathrm{Me}(\mathrm{OH})_{2}^{+} 6,3$ to $\mathrm{pH}_{\text {hydr }} 6.6$ and ytterbium (III) hydroxides at $\mathrm{pH}>\mathrm{pH}_{\text {hydr }} 6.6$ [Chirkst et al. $2009 \mathrm{c}$ ]. In the range of maximum recovery

Table 1. Rare-earth metals distribution coefficients as a function of recovery $\mathrm{pH}$ and sodium chloride concentration

\begin{tabular}{|l|c|c|}
\hline \multicolumn{1}{|c|}{ Parameter } & $\mathrm{Y}(\mathrm{III})$ & $\mathrm{Yb}(\mathrm{III})$ \\
\hline $\mathrm{pH}_{\text {compl }} \mathrm{MeOH}^{2+}$ & 6.3 & 5.8 \\
\hline $\mathrm{pH}_{\text {compl }} \mathrm{Me}(\mathrm{OH})_{2}^{+}$ & 7.0 & 6.3 \\
\hline $\mathrm{pH}_{\text {hydr }}$ & 7.2 & 6.6 \\
\hline \multicolumn{2}{|c|}{$\mathrm{C}_{\mathrm{NaCl}}=0$} \\
\hline Distribution coefficient & 855.6 & 403.7 \\
\hline $\mathrm{pH}$ of maximal recovery & 6.9 & 8.3 \\
\hline $\mathrm{pH}$ of the start of recovery & 6.1 & 6.0 \\
\hline \multicolumn{2}{|c|}{$\mathrm{C}_{\mathrm{NaCl}}=0.01 \mathrm{M}$} \\
\hline Distribution coefficient & 379.5 & 48.3 \\
\hline $\mathrm{pH}$ of maximal recovery & 7.8 & 7.4 \\
\hline $\mathrm{pH}$ of the start of recovery & 6.7 & 5.9 \\
\hline \multicolumn{2}{|c|}{} \\
\hline Distribution coefficient & 9.4 & 12.4 \\
\hline $\mathrm{pH}$ of maximal recovery & 7.0 & 6.7 \\
\hline $\mathrm{pH}$ of the start of recovery & 6.4 & 6.0 \\
\hline
\end{tabular}


Table 2. Yttrium and ytterbium chloro and hydroxo complexes instability constants

\begin{tabular}{|c|c|c|c|c|c|}
\hline Compound & $K_{n}$ & $\Delta_{\text {compl }} G_{298}^{0}, \mathrm{~kJ} / \mathrm{mol}$ & Compound & $K_{n}$ & $\Delta_{\text {compl }} G_{298}^{0}, \mathrm{~kJ} / \mathrm{mol}$ \\
\hline $\mathrm{YCl}^{2+}$ & 0.054 & -7.22 & $\mathrm{Y}(\mathrm{OH})^{2+}$ & $1.56 \times 10^{-8}$ & -44.56 \\
\hline $\mathrm{YbCl}^{2+}$ & 0.110 & -5.46 & $\mathrm{Yb}(\mathrm{OH})^{2+}$ & $4.99 \times 10^{-9}$ & -47.39 \\
\hline
\end{tabular}

$\mathrm{pH}$ of 6.7 ytterbium (III) goes into the froth in the form of $\mathrm{Yb}(\mathrm{OH})_{3}$, because $\mathrm{pH}_{\text {hydr }}$ is $6.6 . \mathrm{pH}$ of recovery onset 6.0 lies in the range of $\mathrm{pH}_{\text {compl }}$ $\mathrm{MeOH}^{2+} 5.8$ and $\mathrm{pH}_{\text {compl }} \mathrm{Me}(\mathrm{OH})_{2}{ }^{+} 6.3$ [Chirkst et al. 2010], therefore, $\mathrm{Yb}^{3+}$ is recovered in a form of $\mathrm{YbOH}(\mathrm{DS})_{2}$.

The influence of chloride ions on the distribution coefficient was explained by comparing chloro and hydroxo complexes instability constants (Table 2). The first ones were calculated using the following formula:

$$
\begin{gathered}
\Delta_{\mathrm{f}} \mathrm{G}_{298}^{0}\left\{\mathrm{MeCl}_{\mathrm{aq}}^{2+}\right\}=\Delta_{\mathrm{f}} \mathrm{G}_{298}^{0}\left\{\mathrm{Me}_{\mathrm{aq}}^{3+}\right\}+ \\
+\Delta_{\mathrm{f}} \mathrm{G}_{298}^{0}\left\{\mathrm{Cl}_{\mathrm{aq}}^{-}\right\}+\mathrm{R} \cdot \mathrm{T} \cdot \ln \mathrm{K}_{\mathrm{n}}
\end{gathered}
$$

by evaluating instability constant from the following equation:

$$
\mathrm{K}_{\mathrm{n}}=\mathrm{e}^{-\frac{\Delta_{\text {compl }} \mathrm{G}_{298}^{0}}{\mathrm{R} \cdot \mathrm{T}}}
$$

Gibbs energy of chloro complexes and lanthanide cations formation in aqueous solution was accepted according to the database [Database TKB]. Hydroxo complexes instability constants were accepted according to data [Chirkst et al. 2009].

When adding chlorides, part of lanthanides binds into non-floating chloro complexes. Decrease in hydroxo complexes part leads to flotation suppression and maximum recovery value shifting to higher $\mathrm{pH}$ values range. As a result, conditions for yttreum and ytterbium separation are provided.

Yttrium (III) cations are bonded into strong non-floating chloro complex, therefore, a significant decrease of distribution coefficients is observed. Because of comparatively high value of ytterbium (III) chloro complex instability constant, a decrease of recovery onset $\mathrm{pH}$ value and maximum recovery $\mathrm{pH}$ value when increasing chlorides concentration is observed.

Because of chloro and hydroxo complexes different stability, different shift of recovery $\mathrm{pH}$ and flotation suppression occur, and, therefore, the conditions for yttrium and ytterbium separation appear. The stronger the chloro complex and weaker the hydroxo complex are, the greater shift towards higher recovery $\mathrm{pH}$ values is.

\section{CONCLUSIONS}

1. During ytterbium ion flotation when adding chloride ions a tendency to $\mathrm{K}_{\text {distr }}$ decreasing and shifting maximum recovery to the region of lower $\mathrm{pH}$ values is observed. Yttrium $\mathrm{K}_{\text {distr }}$ also decreases, and maximum recovery $\mathrm{pH}$ at chloride concentration of $0.01 \mathrm{M}$ shifts to the region of high values, compared to nitrate medium.

2. At maximum recovery $\mathrm{pH}$ yttrium goes into the froth at chloride concentration of $0.01 \mathrm{M}$ in a form of $\mathrm{Y}(\mathrm{OH})_{3}$, and at chloride ions concentration of $0.05 \mathrm{M}$ the $\mathrm{Y}(\mathrm{OH})_{2}$ DS goes into froth. Ytterbium (III) hydroxides are recovered into the froth at maximum recovery $\mathrm{pH}$ at $\mathrm{NaCl}$ concentration of $0.01 \mathrm{M}$, because $\mathrm{pH}_{\text {hydr }}$ 6.6 [8]. In the maximum recovery $\mathrm{pH}$ range of 6.7 with sodium chloride concentration of 0.5 $\mathrm{M}$ ytterbium (III) goes into the froth in a form of $\mathrm{Yb}(\mathrm{OH})_{3}$.

\section{Acknowledgements}

The work is done according to the grant of the President of the Russian Federation for state support of young Russian scientists Project 14.Z56.15.6262-YC "Investigation of the methods effective adsorption-bubble recovery and separation of rare earth elements with the use of surface-active substance from multicomponent solutions of poor technogenic raw materials".

The studies were performed using equipment CCU of the Mining University: atomic absorption spectrometer AA 6300 of the company Shimadzu, optical emission spectrometer with parallel action ICPE-9000 inductively coupled plasma of the company Shimadzu, spectrophotometer UV-VIS Specord 200 of the company Analytik Jena.

\section{REFERENCES}

1. Chirkst D.E., Lobacheva O.L., Berlinskiy I.V. and Sulimova M.A. 2009a. Extraction and separation of ions $\mathrm{Ce}^{3+}$ and $\mathrm{Y}^{3+}$ from aqueous solutions by ion flotation. Journal of Applied Chemistry, 82(8), 1370-1374. 
2. Chirkst D.E., Lobacheva O.L., Berlinskiy I.V. and Sulimova M.A. 2009b. Thermodynamic properties of hydroxocompounds and mechanism of ion flotation cerium, europium and yttrium. Journal of Physical Chemistry, 83(12), 2022-2027.

3. Chirkst D.E., Lobacheva O.L. and Berlinskiy I.V. 2009c. Gibbs Energies of formation of hydroxides of lanthanides and yttrium. Journal of Physical Chemistry, 84(12), 2047-2050.

4. Chirkst D.E., Lobacheva O.L., Berlinskiy I.V. and Cheremisina O.V. 2010. Thermodynamic investigation of the ytterbium ion flotation. Bulletin of St. Petersburg State University, 4(2), 137-142.

5. Danilov A.S., Smirnov Y.D. and Pashkevich M.A. 2015. Use of biological adhesive for effective dust suppression in mining operations. Jour- nal of Ecological Engineering, 16(5), 9-14. DOI: $10.12911 / 22998993 / 60448$

6. Database TKB. Parameters and definitions // http:// www.chem.msu.su

7. Gol'man A.M. 1982. Ion flotation. Nedra, pp. 144.

8. Kreshkov A.P. 1976. Fundamentals of analytical chemistry. Theoretical basis. Quantitative analysis. Chemistry, pp. 480.

9. Savin S.B. 1966. Arsenazo III. Atomizdat, pp. 265.

10. Timofeev S.V., Materova V.A., Arkhangelskiy L.K. 1978. Vestnik LGU. A Series of Physics, Chemistry, 3(16), 139-141.

11. Zolotov Y.A. (Ed.) Fundamentals of Analytical Chemistry. Book 1. General questions. Methods of separation. Higher School, 2004, pp. 360. 